Journal of Social Sciences 4 (3): 222-228, 2008

ISSN 1549-3652

(C) 2008 Science Publications

\title{
Investigating Mechanisms of Marginal Settlement Life Improvement
}

\author{
Hamid Movahed Mohammadi, Yaser Mohammadi ,Mehdi Rahimian and Navid Loghmani \\ Department of Agricultural Extension and Education, \\ Agricultural Economics and Development College, Tehran University, Karaj, Iran
}

\begin{abstract}
The main purpose of this research was to investigate mechanisms to improve marginal settlement life in Koohdasht County in Lorestan province. This research was a sort of the survey studies and a questionnaire was compiled for collection of data. Statistical population of this study was included 1560 households; also sampling method was a sort of random sampling. Number of sample size was estimated 85 households. Questionnaire's reliability was confirmed through computing Cronbach's alpha coefficient which was 0.85 . Face validity of questionnaire was confirmed by some Tehran university agricultural extension and education department scientific board members. Also data analyzed by WINspss 11.5. The results of research revealed that marginal area residents had not good financial situation but they undertook great supporting burden and in point of view access to services and life conditions had not good situation. Therefore improvement of life conditions of marginal settlement life such as fundamental infrastructure include communication systems and sanitation offloading system recognized as the most important mechanisms of marginal settlement improvement according to results of priority setting of marginal settlement situation mechanisms. Also the results of factor analysis showed that 7 main mechanisms were be effective in term of marginal settlement life improvement that in order to importance were included servicing and life condition improvement, credit-economic, civil and legal, control and prevention, population and migration control, infrastructures improvement and hygiene situation.
\end{abstract}

Key words: Marginal settlement life, mechanisms of situation improvement, servicing, marginal area residents, Koohdasht County

\section{INTRODUCTION}

Nowadays, civic phenomenon occupied the entire earth planet ${ }^{[7]}$ and one of the human society problems which most of the cities is construction of unusual and non standardized habitats by immigrants and individuals who settled down in marginal areas due to different reasons. This will lead to civic discordant texture and also cultural-social problems ${ }^{[4]}$. Today, all worlds cities is involved marginal settlement ${ }^{[5]}$. According to the estimation of international organizations which are active in human settlement, about one billion of worlds population in marginal areas or live an informal settlement ${ }^{[3]}$. Some of the researches believed that the main reason of marginal areas is the immigration of individuals who seeks the better job and higher income opportunities due to their inappropriate economical situation. So these researchers mainly investigate the immigrations reasons. For example Digard Bilzebro said that political, economical, social, cultural and psychological factors are important in immigration. GHorakhloo and sharifi believed that internal immigration has been impressed by social and economical developing plans ${ }^{[2]}$. But according to Sedigh Sarvestavi opinion, marginal settlement is dependent on two culture rural and civic culture, at the same time is not solely dependent on just one of them $^{[10]}$. To decrease the marginal settlements difficulties and its mentioned negative effects, governments should take steps in two fields. First they should decrease the expansion of this phenomenon by investigating the factors which have some effects on marginal settlement. Then they should improve the conditions of marginal areas. To sum up, there are three methods available for civic planners and managers in Iran toward civic balanced development. These methods are as follows:

- Imagination of keeping immigrants far away from municipal areas or trying to do that

- Ignoring marginal settlement and assuming that there is not such a thing and waiting till this problem be solved automatically

Corresponding Author: Yaser Mohammadi, Department of Agricultural Extension and Education, Agricultural Economics and Development College, Tehran University, Karaj, Iran 
- Accepting the marginal settlement as a reality and then guiding and controlling this phenomenon via civic developmental plans, in such a way that the new population which is sloping to municipal areas is used to increase national wealth and development. So, the new immigrant population is employed in urbanity processes and development of municipal areas and this additional of population is used to increase comfort and welfare. The first solution is rejected and the second solution is ignoring the reality. But the third one, recognize the marginal settlement, accept it and try hard to prevent and handle it. In this case, social engineering, empowering, increasing the accessibility to social services and having civic sustainable developmental strategy will be considered ${ }^{[6]}$. Marginal settlement and informal settling, is not a transient phenomenon with just limited effects. Its extension and regeneration can be observed which indicates inefficiency of solutions and usual civic politics and demands for new actions and politics ${ }^{[9]}$. With due attention to globalization of marginal settlement problem and its related effects on municipal areas such as economical, social and cultural difficulties, different studies had been directed in this field which investigates the improvement of marginal settlements situations. For instance, Ebrahimzadeh et al. ${ }^{[1]}$ believed that improvement of the situations of Karimabad, Zahedan marginal residents is dependent on mechanisms such as: decreasing the natural growth rate of population, increasing and balancing the immigrations from rural areas to municipal areas, supporting the small cities of provinces and giving constructive budgets to them, preventing the entrance of external immigrants, recognizing the citizenship rights of marginal areas residents, making job opportunities, wise civic management to settle low income individuals and being ready to accept them in municipal areas, improving frames along with social,economical and cultural empowering the marginal areas residents, municipal councils control on house buildings of marginal areas, increasing laborers skills of marginal areas and improvement of life conditions in marginal areas. Furthermore, Naghdi et $a l .{ }^{[6]}$ believed that the basic solutions for marginal settlement problem are the balanced and sustainable civic development, providing social safety and justice, increasing economical and cultural inequality between different groups of the society and different regions of the country. Poorahmad et al ${ }^{[8]}$ also said that establishing local councils in municipal parishes and paying more attention to low-income groups in the ruined places of the city in order to reach the social and economical development and growth are parts of mechanisms that can be used to solve the marginal settlement problem. To solve problems of marginal areas residents, first the mechanisms of improvement of these areas should be investigated from resident's point of view. Then the problems can be solved via regular, subtle and continued planning and performance of these plans. Koohdasht County is located in Lorestan province and like the other cities of Iran is suffered of marginal settlement negative effects and problems and the marginal areas located around this city have been developed in recent years. So, this study will investigate the effective mechanisms which can be useful to improve the situations of marginal areas residents of Koohdasht form the resident's point of view.

\section{MATERIALS AND METHODS}

The research method of this study is a sort of applied studies with a view to goals. It is a field study with a view to variables control degree and is correlation- descriptive study with a view to information analysis methods. The study theoretical framework was gained using librarian study method, electronic resources and field studies of the region. The region in our study was Koohdasht, a city in Lorestan province, Iran. The statistical population of study is marginal areas residents of Koohdasht and includes 1560 rural families of Koohdasht. Our samples selected by random sampling method. Using Cochrans formula, sample size was estimated about 85 individuals. Questionnaire was used to gather the data and information. After the pilot studies on farmers, The Cronbachs alpha coefficient was used to compare the mechanisms related to improvement of situations of marginal areas residents. The Croncachs alpha value was 0.85 which showed an acceptable reliability. Data analysis was done in tow levels of descriptive statistics frequency, distribution, percentage, mean and priority setting and inferential statistics, factor analysis, using WINSPSS 11.5. To compare the mechanisms related to improvement of situations of marginal areas residents, after reviewing the articles, counseling with professionals and experts and considering the region situation and scale composed of 23 mechanisms of marginal settlement was developed and given to the marginal areas residents, so that they could be able to express their views regarding these mechanisms. 


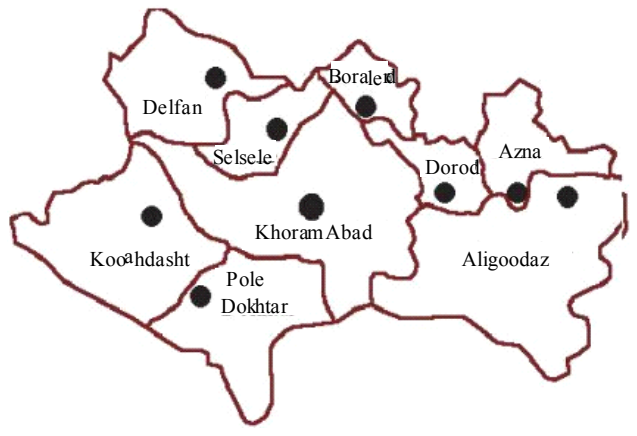

Fig. 1: Lorestan province

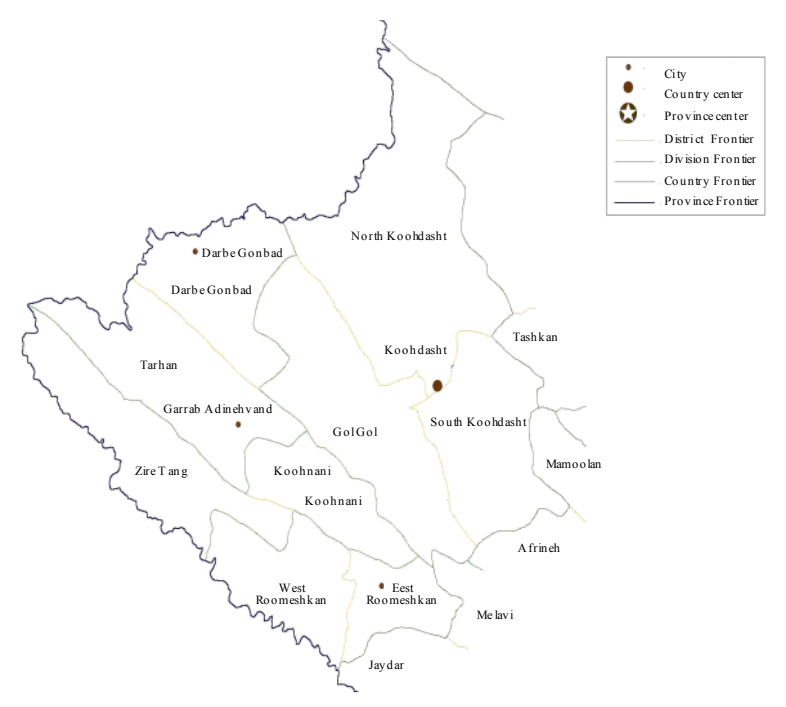

Fig. 2: Koohdasht County

The region situation: Koohdasht County has a surface of $3904 \mathrm{~km}^{2}$ and its population is equal to 188964 individuals. This county is located in west of Lorestan province. Its economy is mainly dependent on agriculture and animal husbandry. That is why it has a good situation and it's agricultural and animal husbandry products are considered as exports. This county has an ancient history. Archaeologist's researches showed that this county was one of the primary habitats of human beings. Koohdasht has 4 divisions and 9 rural shows in Fig. 1 and 2.

\section{RESULTES AND DISCUSSION}

Social and individual characteristics: Results of social and individual characteristics investigation of marginal areas residents showed that most of them is in middle-aged group 31-60 years old and their age average is 41 years old. Majority of them $(86 \%)$ are married. the results also showed that the average of the number of families sons and daughters are 2 and 1.5 respectively. But most of the families (41.2\%) had 3-4 sons and about 2 girls. According to the results, the average of the number of individuals supported by a family is 5 . Most of the families (58.8\%) supported more than 5 persons. regarding their educational level, most of the marginal areas residents $(35.3 \%)$ are literate. regarding their jobs, about 40 percent of marginal areas residents suffer from unemployment. the majority of the persons who occupied a job (55.1\%) were simple workers and peddlers. furthermore the results indicates that more than $70 \%$ of marginal areas residents have an income lower than 2 million Rials per month. Regarding their housing, more than $(50 \%)$ of marginal areas residents were living in their parental house or in a rent house. most of them (58.8\%) had immigrate from another part of the same city to the marginal areas. the other results showed revealed that most of marginal areas residents $(37.6 \%)$ had to leave their pervious place due to financial weakness most of them spent their free time watching TV.

Priority setting of mechanisms related to improvements of marginal settlements situations in Koohdasht County: To understand the priorities of mechanisms related to improvements of marginal settlements situations from responders point of view, 23 questions were presented to responders. Then with due attention to the calculated mean, priorities were set. The results are shown in (Table1).

The results of priority setting of mechanisms related to improvements of marginal settlements situations in Table 1 showed that improvement of life conditions of marginal areas residents such as basic substructures like communication systems and sanitation offloading systems, complete and exact study of immigration with due attention to immigration from rural areas to municipal areas to understand the main reasons of immigration, decreasing and balancing the immigrations, increasing accessibility of social services and making job opportunities for residents of marginal areas were recognized as first five priorities of mechanisms related to improvements of marginal settlements situations from responders point of view. As the results indicate, improvement of situations of marginal areas residents is so important in their point of view. This result is not so strange. Looking at the marginal area resident's situations and their life environment, it can be easily inferred that their life condition is so complicated and the services are undesirable. Therefore, more attention should be paid to improve the life conditions of marginal areas residents. 
Table 1: Priority setting of mechanisms related to improvements of marginal settlements situations from responder's point of view

\begin{tabular}{|c|c|c|}
\hline Mechanisms related to improvements of marginal settlements situations & Mean & Priority \\
\hline $\begin{array}{l}\text { Improvement of life conditions of marginal areas residents such as basic substructure } \\
\text { Like communication systems and sanitation offloading systems. }\end{array}$ & 4.56 & 1 \\
\hline Complete and exact study of immigration with due attention to immigration & 4.33 & 2 \\
\hline From rural areas to municipal areas to understand the main reasons of immigration. & & \\
\hline Decreasing and balancing the immigrations. & 4.12 & 3 \\
\hline Increasing accessibility of social services. & 4.11 & 4 \\
\hline Making job opportunities for residents of marginal areas. & 4.01 & 5 \\
\hline Paying more attention to public hygiene in marginal areas. & 4.01 & 6 \\
\hline Empowering the marginal areas residents to be able to make job opportunities. & 3.99 & 7 \\
\hline Improvement of city physical substructures. & 3.94 & 8 \\
\hline $\begin{array}{l}\text { Emphasis on professional training projects and seeking jobs, family planning guiding-training } \\
\text { center, construction of kindergarten, construction of public room in marginal areas. }\end{array}$ & 3.92 & 8 \\
\hline Recognizing citizenship of marginal areas residents. & 3.86 & 10 \\
\hline $\begin{array}{l}\text { Presenting professional training to increase skills of laborers in marginal areasresidents and be } \\
\text { useful in economics of official section and decreasing the employment in unofficial section. }\end{array}$ & 3.84 & 11 \\
\hline $\begin{array}{l}\text { Planning for activities of private and public sections to provide cheap houses and giving loans } \\
\text { to marginal areas residents. }\end{array}$ & 3.75 & 12 \\
\hline $\begin{array}{l}\text { Increasing the welfare and environmental hygiene levels in rural areas and small and } \\
\text { intermediate cities. }\end{array}$ & 3.72 & 13 \\
\hline Providing optimum job opportunities in rural areas,small and intermediate cities. & 3.71 & 14 \\
\hline Making more accessibility to credit resources for marginal areas residents. & 3.64 & 15 \\
\hline Increasing the housing cooperative societies with collaboration of related ministry. & 3.49 & 16 \\
\hline Improving the agricultural and economical growth such as increasing the agricultural credits. & 3.42 & 17 \\
\hline Decreasing the population growth rate. & 3.35 & 18 \\
\hline Paying attention to kids and womens rights. & 3.21 & 19 \\
\hline More control of municipality on housing construction projects in marginal areas. & 3.20 & 20 \\
\hline Elimination of the broking problem and correcting the consumption pattern in the region. & 3.19 & 21 \\
\hline Improvement of the situations of small and intermediate cities of the province. & 3.09 & 22 \\
\hline Preventing the illegal constructions which have not construction license. & 2.81 & 23 \\
\hline
\end{tabular}

Scale: Not at all(0), Low(1), Very low(2), Intermediate(3), High(4), Very high(5)

Furthermore, studying the immigration phenomenon, its reasons and also its control are the next priorities of mechanisms related to improvements of marginal settlements situations. More attention should be paid to problem of excessive immigration to cities, marginal settlement around the cities and the reasons of these immigrations. Useful administration should be applied regarding these problems. Making job opportunities and improving the economical situation of marginal areas residents is important from responder's point of view. With due attention to their weak economical situation, they hope that authorities will provide job opportunities. So the basis of making job opportunities should be available for marginal areas residents especially for youth so that they would not seek false jobs.

Factor analysis of mechanisms related to improvements of marginal settlement situations in Koohdasht: To determine the mechanisms related to improvements of marginal settlement situations in Koohdasht, the variables entered factor analysis. With due attention to KMO statistics and Bartletts test, the degree of data fitness is shown in Table 2 which indicates the fitness of variables Table 2 .
Table 2: KMO value and Bartlett's test

\begin{tabular}{llll}
\hline Factor analysis & KMO & Bartlet test & Sig \\
\hline $\begin{array}{l}\text { Mechanisms related to improvements } \\
\text { Of marginal settlements situations in }\end{array}$ & 0.734 & 2321.812 & 0.000 \\
Koohdasht & & & \\
\hline
\end{tabular}

Table 3: Extracted factors with special value, variance percentage and their cumulative variance percentage

\begin{tabular}{llll}
\hline Factors & $\begin{array}{l}\text { Eigen } \\
\text { value }\end{array}$ & $\begin{array}{l}\text { Eigen value of } \\
\text { variance percentage }\end{array}$ & $\begin{array}{l}\text { Cumulative } \\
\text { variance percentage }\end{array}$ \\
\hline 1 & 3.26 & 15.55 & 15.55 \\
2 & 3.20 & 15.25 & 30.80 \\
3 & 2.04 & 9.70 & 40.50 \\
4 & 1.67 & 7.95 & 48.45 \\
5 & 1.32 & 6.30 & 54.75 \\
6 & 1.30 & 6.20 & 60.95 \\
7 & 1.20 & 5.73 & 66.68 \\
\hline
\end{tabular}

According to the results of factor analysis of mechanisms related to improvements of marginal settlement situations in Koohdasht Table 3, these mechanisms are classified in 7 factors. As a whole, these seven factors express demonstrate $(66.68 \%)$ of total variance. First factor servicing and improvement of life situations, with special value of 3.26 , demonstrates more than $(15 \%)$ of total variance and indicates high importance of this factor. Other factors demonstrate $(15.25,9.70,7.95,6.30,6.20$ and $5.73 \%)$ 
Table 4: determination of mechanisms related to improvements of marginal settlement's situations, statements and related factor loads

\begin{tabular}{lll}
\hline Factor name & Variable & Factor load \\
\hline $\begin{array}{l}\text { Servicing and improvement } \\
\text { of life condition }\end{array}$ & $\begin{array}{l}\text { Increasing accessibility of social services } \\
\text { Improvement of life conditions of marginal areas residents such as } \\
\text { basic substructures like communication systems and sanitation offloading systems }\end{array}$ & 0.69 \\
& $\begin{array}{l}\text { Planning for activities of private and public sections to provide cheap } \\
\text { houses and giving loans to marginal areas residents }\end{array}$ & 0.66 \\
& Increasing the housing cooperative societies with collaboration of related ministry & 0.65 \\
Economical-credit & Empowering the marginal areas residents to be able to make job opportunities & 0.64 \\
& Making job opportunities for residents of marginal areas & 0.80 \\
& Making more accessibility to credit resources for marginal areas residents & 0.62 \\
Legal & Improving the agricultural and economical growth such as increasing the agricultural credits & 0.54 \\
& Paying attention to kids and womens rights & 0.72 \\
Control and prevention & Recognizing citizenship of marginal areas residents & 0.64 \\
& preventing the illegal constructions which have not construction license & 0.78 \\
Immigration and population & More control of municipality on housing construction projects in marginal areas & 0.70 \\
Control & decreasing the population growth rate & 0.83 \\
& Complete and exact study of immigration with due attention to immigration from rural areas & 0.55 \\
Improvement of substructures & to municipal areas to understand the main reasons of immigration & 0.41 \\
Hygiene situation & Decreasing and balancing the immigrations & 0.76 \\
& Improvement of city physical substructures Increasing the welfare and & 0.74 \\
\hline
\end{tabular}

of total variance respectively. Regarding the results of mechanisms of servicing and improvement of life condition is the most important mechanism related to improvements of marginal settlement situations in Koohdasht. Table 4 shows factors nomenclature, related variables and related factor loads.

As Table 4 shows, servicing and improvement of life condition is the most mechanisms related to improvements of marginal settlement situations from responder's point of view. Then, credit-economical is the second most important one to improve life condition of marginal areas residents. According to resident's economical and financial problems, the importance of mechanism becomes more apparent. The legal mechanism is the third important mechanisms related to improvements of marginal settlements situations. Most of residents claimed that their citizenship rights were ignored. So, more attention should be paid to their rights. Control and prevention which is the duty of municipality, is considered as forth important mechanism which has effects on improvement of marginal areas residents situations. Checking illegal constructions in marginal areas by municipality could help to control the excessive construction and housing in marginal areas. Immigration and population control is the next mechanism related to improvements of marginal settlements situations. Lack of lots of substructures and existence of hygiene problems in marginal areas environment make it necessary to consider the last two mechanisms of marginal areas situations improvement. The degree of mechanisms importance is shown in Fig. 3.

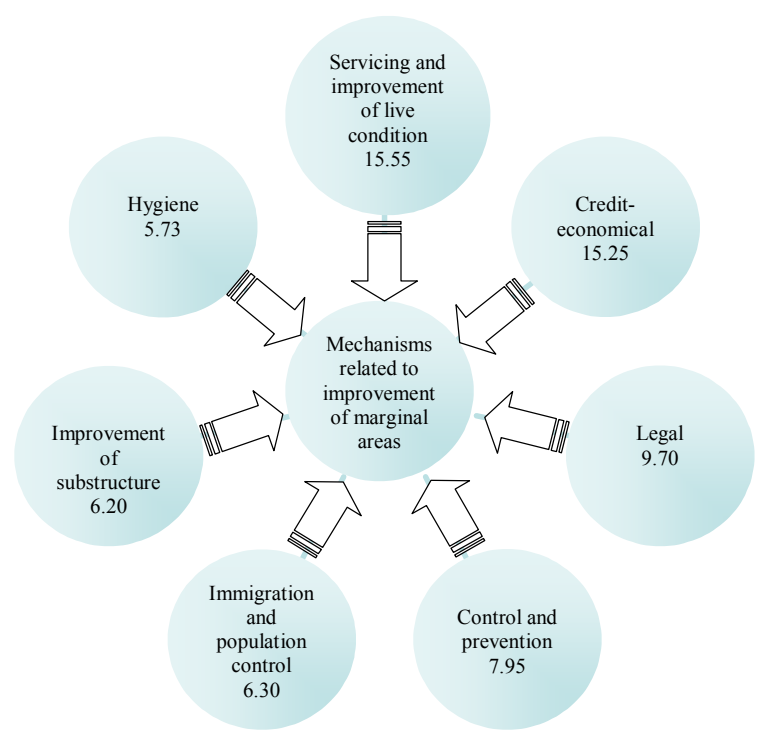

Fig. 3: Categories of mechanisms related to improvement of marginal areas situations

\section{DISCUSSION}

According to the results, marginal areas residents in Koohdasht had special social and individual characteristics which indicate their inappropriate life situations. Most of them did not have good financial situation. They had no job or had just a temporary job while they support more than five individuals. So, most of them lived in their parental house or in a rent house. Lack of suitable jobs lead to involvement of youth in 
unsuitable jobs such as drug smuggling which will be the basis for their addiction. youths addiction will cause insecurity in cities which will lead to lots of problems for citizens and governments. Insecurity in cities and lack of lots of services in marginal areas in the other hand make the residents to live the worst condition. the results of priority setting of mechanisms related to improvement of marginal areas situation is logical because improvement of life conditions of marginal areas residents like construction of communication systems and sanitation offloading systems is the first priority from residents point of view. With due attention to all problems and awful life situations in these areas, this mechanism should has the first priority. But all the problems will not be solved via this mechanism and the main reason of these problems should be discovered.

Excessive immigration from rural areas to municipal areas is the main reason of lots of problem and marginal settlement. Therefore, studying immigration phenomenon, its reasons and its control are important mechanisms which should be considered by authorities. As it can be seen in priority settings results, $2^{\text {nd }}$ and $3^{\text {rd }}$ mechanisms express this subject.

The other subject that should be considered is that most of the marginal areas residents have not a good financial situation and the economical poverty will lead to cultural poverty and lots of social problems. Therefore the residents should be economically being supported via creating job opportunities to prevent lots of social problems. This mechanism also has a high importance in priority setting of mechanisms related to improvement of marginal areas situations. The results of factor analysis also improved lots of our previous results. The mechanism of servicing and improvement of life condition as the first priority indicates that this mechanism has a high importance in improvement of marginal settlements situations. This was also proved by results of priority setting. According to the economical difficulties of marginal areas residents which were discussed before, it was expected that credit- economical mechanisms be in the second place in priority setting so that its importance would be noticed. Creating job opportunities and giving lowprofit loans to empowerment marginal areas residents could help them to improve their lives. But many of their problems is related to this fact that they are deprived of their citizenship rights. it is necessary that authorities recognize residents citizenship rights and consider kids and women rights. Municipality should also controls and prevents illegal housing constructions in marginal areas to prevent the overpopulation in these areas. To control the population growth rate, immigration should be defeated. So, the reasons of immigration should be studied to provide the basis of immigration control. Improvement of physical substructures and hygiene situation in marginal areas is one of the other mechanisms that are important to improve marginal areas situation. The factor analysis also proved these results.

\section{CONCLUSION}

According to the results of primary settings of mechanisms related to improvement of marginal settlements situation, improvement of life condition of marginal areas residents such as construction of communication systems and sanitation offloading systems has the first priority. In the other hand, the fist factor of the factor analysis results is the mechanism of servicing and improvement of life condition. So, it is suggested that authorities pay attention to providing services and facilities to improve the life condition of marginal areas residents.

The income of the majority of marginal areas residents is less than two million rials per month and more than $(50 \%)$ of them have no job and income. In the other hand, creating job opportunities is one of the first priorities of the mechanisms related to improvement of marginal settlements situation. In addition, according to the results of factor analysis of mechanisms, credit-economical mechanism is in the second place of importance. So it is suggested that authorities create job opportunities in rural areas for residents to earn more money which leads to preventing the marginal settlement improving agricultural development in rural areas may help creating job opportunities for villagers.

According to the results of priority settings of the mechanisms related to improvement of marginal settlements situation, complete study of immigration with due attention to immigration from rural areas to municipal areas to understand the factors of immigration and immigrations decreasing and controlling is in the $2^{\text {nd }}$ and $3^{\text {rd }}$ place of importance. This indicates that these mechanisms are so important from marginal areas residents point of view. So it is recommended that researchers investigate the reasons of immigration and authorities control and balance the excessive immigrations.

The results of factor analysis indicate that legal mechanism is one of the important mechanisms related to improvement of marginal settlements situation. So it is suggested that authorities recognize the citizenship rights of marginal areas residents to help improvement of their situations. 
According to the results of factor analysis of the mechanisms related to improvement of marginal settlements situation and categories of factors with due attention to their importance and the percentages of variance which were demonstrated by them,It is recommended that authorities pay attention to their importance coefficient to help improvement of marginal settlements situations.

\section{REFRENCES}

1. Ebrahimzadeh, E., F. Barimani and Y. Nasiri, 2004. Marginal settlement, civil abnormalities and mechanisms for solving, case study: Karimabad, Zahedan. Geograph. Develop. J., 1: 121-142.

2. GHorakhloo, M. and A. Sharifi, 2003. Appearance, physical revolution and social, economical situation of marginal settlement (Case study: Iran, Ahvaz, 2ain region). Geograph. Res. J., 2: 1-15.

3. M. Hadizadeh, Marginal settlement and mechanisms for organizing in world. Azar barzin, 2004, p. 336.
4. Masudifar, R., 2007. Influence of marginal settlement on crime occurrence. http://hoqouq.com/article262.html

5. Mumtaz Babar, 2001. Why cities need slums. Habitat Debate, 7: 15-22

6. Naghdi, A. and R. Sadeghi, 2006. Marginal settlement. Challenge faced civil sustainable development with emphasized on Hamadan province. J. Soc. Welfare, 5: 213-235

7. Y. Phillalkove, Civil Sociology, translated by A. Nikgohar. Agah, 2004, p. 354.

8. Poorahmad, A. and A. SHamaee, 2001. Physical development of Yazd province and its impact on old population structure of Yazd province. J Soc. Sci., 2: 3-22.

9. Sarrafzedeh, M., 2002. Toward theory for organizing of informal habitation. Haft Shahr J., 4: 21-45.

10. Sedigh Sarvestani, R., 2003. Marginal settlement and security. In: Article Collection of Development and Public Security Symposium, 2003, Iranian Information and Documentation Center, Tehran, Iran, p. 112-121 